\title{
Emigração e desenvolvimento em Portugal: o caso da província da Beira Alta (1890-1939)
}

António Rafael AMARO ${ }^{1}$

\section{RESUMO}

O presente artigo trata da emigração de uma região de Portugal, a Beira Alta, que teve como principal destino o Brasil. Serão identificados e caracterizados, durante cinco décadas, os principais fluxos migratórios, os destinos, os perfis etários, profissionais, de género e de instrução dos emigrantes. Pretende-se, ainda, analisar o impacto sociodemográfico e económico da emigração no desenvolvimento económico da Beira Alta.

Palavras-Chave: Emigração; Portugal, Brasil, Desenvolvimento regional.

\section{Emigration and development in Portugal: the case of the province of Beira Alta (1890-1939)}

\begin{abstract}
This article deals with the emigration of a region of Portugal, Beira Alta, whose main destination was Brazil. The main migratory flows, destinations, age, professional, gender and migrant education profiles will be identified and characterized over five decades. It is also intended to analyze the socio-demographic and economic impact of emigration in the economic development of Beira Alta.
\end{abstract}

Key words: Emigration; Portugal, Brazil, Regional development.

\section{INTRODUÇÃO}

A emigração em Portugal tem sido considerada por muitos autores como uma questão estrutural e estruturante da sociedade portuguesa contemporânea (ALMEIDA e BARRETO, 1970; SERRÃO,1977; GODINHO,1978). Esta perspetiva sociológica contribuiu para uma explicação mais consentânea com a complexidade deste fenómeno e colocou a necessidade que os portugueses tiveram de emigrar como uma variável essencial na compreensão de Portugal no mundo como país semiperiférico. Ficou claro, desde logo, que a emigração não se ficou a dever a um qualquer determinismo genético ou modo de ser português, como alguns ilusoriamente pretenderam fazer crer, mas a incapacidades próprias para evitar que as disfunções políticas e socioeconómicas estruturais que atravessaram, sem exceção, todos os regimes nos últimos duzentos anos: monarquia constitucional (1820-1910); I República (1910-1926); Estado Novo (1926-1933-1974) e Democracia (1974-2018). Ainda que os diferentes fluxos migratórios 
tivessem tido (e tiveram) motivações, contextos históricos e destinos diferentes, é possível, ainda assim, encontrar em todos eles uma permanência estrutural incontornável: a emigração como solução de recurso dos portugueses (falamos da emigração involuntária, por causas económicas e sociais) e as dificuldades que Portugal tem demonstrado para se libertar da sua condição semiperiférica no mundo (PEREIRA, 1981; SANTOS, 1993). Durante longos períodos, nos últimos dois séculos da sua história, Portugal viu-se obrigado a conviver com uma espécie de «economia subsidiada» externamente, beneficiando economicamente das importantes remessas dos seus emigrantes, mas tardando em encontrar uma solução para este problema estrutural (ARROTEIA, 1983; LEEDS, 1983; COSTA e PORTO, 1984; SILVA e outros, 1984; LEITE, 1987; BAGANHA, 1988; ALVES, 1989 e 1994).

É neste quadro teórico que procuraremos compreender a emigração da Província da Beira Alta, num contexto histórico e temporal bem determinado (1890-1939), marcado por intensos fluxos migratórios que tinham como destino o Brasil. A Beira Alta situa-se geograficamente no Centro Interior de Portugal e dela fazem parte os distritos de Viseu e da Guarda ${ }^{2}$. Este enfoque regional permite-nos evidenciar dois aspetos que consideramos teórica e metodologicamente nucleares neste trabalho: por um lado, pesquisar com uma malha mais fina as especificidades da emigração deste território e, por outro, avaliar as suas consequências económicas numa província que apresentou os mais elevados fluxos migratórios (AMARO, 2006). É reconhecido pela literatura que a emigração tem efeitos socioeconómicos muito diferentes, dependendo se falamos de regiões ou de espaços nacionais. Os benefícios económicos e financeiros que resultam das remessas dos emigrantes, por exemplo, são bastante assimétricos, prejudicando por norma as regiões mais pobres e que, curiosamente, são muitas vezes as que mais contribuem para a emigração. Os tão propalados efeitos macroeconómicos positivos das remessas - o equilíbrio da balança de pagamentos e das contas públicas, ou mesmo o crescimento do PIB - raramente chegam às regiões mais deprimidas. $\mathrm{O}$ grosso das poupanças dos emigrantes, como foi o caso em Portugal, acabou por ser investido nas regiões mais ricas, onde o capital é naturalmente mais reprodutivo, acabando por beneficiar mais estas e contribuindo para agravar progressivamente as assimetrias regionais (GODINHO, 1978:30; PORTO, 1984, 518).

A Beira Alta caracterizou-se por ser uma das províncias portuguesas que, entre 1890 e 1939, mais se distanciou da média de desenvolvimento do país (AMARO, 2006). Com base nesta

\footnotetext{
${ }^{2}$ A Província da Beira Alta funcionou como unidade administrativa e autárquica, entre 1936 e 1959 , integrando os distritos de Viseu (capital) e da Guarda. Atualmente é uma das 11 províncias históricas de Portugal e não tem qualquer função autárquica ou administrativa (v. mapa em anexo).
} 
realidade, é nosso principal objetivo analisar:1) a dimensão e os principais ciclos do fluxo migratório da Beira Alta no período entre 1890-1939; 2) caracterizar o perfil social dos emigrantes e os principais locais de destino; 3) aferir da relação entre desenvolvimento regional e emigração, tendo por base a realidade e os indicadores económicos e sociais disponíveis sobre a Beira Alta.

\section{A EMIGRAÇÃO DA BEIRA ALTA}

Em 1891, O Comércio de Viseu, o mais influente periódico da cidade, evidenciava grande preocupação com o número de emigrantes que abandonavam a região da Beira Alta. Ficamos também a saber que nos finais do século XIX se estava a operar uma mudança no perfil dos emigrantes que escolhiam como destino o Brasil, vislumbrando-se também nos argumentos do articulista uma tentativa de desencorajar os que viam naquele país uma solução para falta de trabalho e pobreza que grassavam na região. Ficam bem evidentes os principais traços dos emigrantes portugueses:

Hoje a questão muda de figura, porque nem o Brasil já pode dar o que deu em tempo, nem a maioria dos nossos emigrantes pode competir com os das outras nações. A maior parte dos portugueses que hoje vão para o Brasil pertencem à classe dos agricultores que, ou vão já engajados para o trabalho das roças, que dantes era feito pelos escravos, ou se entregam à sorte do primeiro especulador que lhes aparece ao desembarque, oferecendo-lhe mundos e fundos para depois os deixarem morrer à miséria ${ }^{3}$.

Em nítido contraste com um passado recente, os portugueses que agora emigravam para o Brasil tinham menores qualificações e tinham como principal destino a agricultura. Há neste discurso alguma verdade, sobretudo se pensarmos que os portugueses iam concorrer neste período com outros emigrantes europeus. Porém, a preocupação maior era com a falta de braços que se começava a fazer sentir na região e com o impacto que isso tinha na subida dos salários na agricultura. Entre 1890 e 1939, partiram da Beira Alta 281.509 emigrantes legais. Números significativos para dois distritos do interior de Portugal que estavam longe de apresentar uma densidade demográfica elevada. Trata-se de um fluxo emigratório de grande intensidade, representando cerca de 1/5 do total da emigração portuguesa no mesmo período. Entre 1890 e 1939, entre cada 100 emigrantes legais, 19,1 eram originários da Beira Alta.

A Beira Alta fazia parte dos territórios do continente português donde mais se emigrava e o distrito de Viseu estava entre os que registavam as médias anuais mais elevadas de emigração

\footnotetext{
${ }^{3}$ O Comércio de Viseu, n. 475, 1 de fevereiro de 1891.
} 
legal. A única exceção foi a década de 1920-1929, período em que o distrito do Porto atingiu valores médios mais elevados (EVANGELISTA, 1971,94). A informação reunida no quadro 1 ganha ainda mais relevância se tivermos em consideração o seguinte: na Beira Alta o crescimento efetivo dos seus residentes esteve sempre muito longe de acompanhar os altos valores do fluxo emigratório. Entre 1890 e 1940, os distritos de Viseu e da Guarda registaram um crescimento efetivo de 113781 residentes, valores que apenas equivalem a 40\% da emigração registada. Com este comportamento demográfico apenas mais dois outros distritos portugueses: Bragança e Vila Real (EVANGELISTA, 1971, 108). Não certamente por acaso, dois distritos do interior norte de Portugal que, no final da década de 1930, acompanhavam a Beira Alta na cauda do (sub)desenvolvimento económico.

\section{Quadro 1 - Emigração legal na Beira Alta e Portugal (1890-1939)}

\begin{tabular}{|c|c|c|c|c|}
\hline \multirow[b]{2}{*}{ Anos } & \multicolumn{2}{|c|}{ Beira Alta } & \multicolumn{2}{|l|}{ Portugal } \\
\hline & Total por década & Média anual & Total por década & Média anual \\
\hline 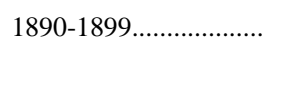 & 45083 & 4508,3 & 278209 & 27820,9 \\
\hline $1900-1909 \ldots \ldots \ldots \ldots$ & 54601 & 5460,1 & 307987 & 30798,7 \\
\hline 1910-1919......................... & 83314 & 8331,4 & 400507 & 40050,7 \\
\hline 1920-1929....................... & 72854 & 7285,4 & 366339 & 36633,9 \\
\hline 1930-1939 ...................... & 25657 & 2565,7 & 119222 & 11922,2 \\
\hline 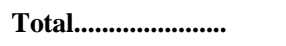 & 281509 & 5630,1 & 1472264 & 29445,2 \\
\hline
\end{tabular}

Fonte: (AMARO, 2006)

A emigração na Beira Alta, ainda que mais intensa, teve uma evolução muito próxima das tendências registadas no conjunto do país. Esta correlação parece confirmar, entre outras coisas, que as causas profundas (internas e externas) da emigração, mais do que regionais ou sectoriais, são nacionais e internacionais. Tal como no resto do país, os fluxos migratórios provenientes da Beira Alta foram sempre em crescendo até à década de vinte, com um importante pico nos anos de 1912 e 1913. A I Guerra Mundial interrompeu por uns anos este intenso fluxo, para de novo se reanimar entre 1920-1929. A crise económica e financeira de 1929 e a situação política internacional da década de trinta mudaram completamente o quadro internacional, reduzindo os fluxos migratórios para valores inferiores aos dos finais do século XIX. Note-se que, no caso português, não obstante o importante refluxo emigratório dos anos de Guerra (19141918), a década de 1910-1919 registou, ainda assim, os valores globais mais altos. Números em grande parte explicáveis pela «debandada» dos anos de 1912-1913, em que emigravam famílias 
inteiras. A «debandada» para o Brasil neste período, deste modo denominada pela imprensa da Beira Alta, era assim explicada: "escusamos de folhear os nossos livros de economia política para estudar as causas do crescimento da nossa emigração para o Brasil, porque elas estão à vista dos menos perspicazes logo que não vivam afastados das classes sociais. As causas principais são a pequenez dos salários de cá e a sedução com as viagens gratuitas que parte de lá”4 .

Como já referimos, da Beira Alta fazem parte duas circunscrições distritais, os distritos de Viseu e da Guarda. O distrito da Guarda, para além de mais pequeno em superfície, tinha também menos população. Com uma densidade populacional menor e representando, em 1940, apenas 38,66\% da população total da Beira Alta, viu sair 94124 emigrantes, correspondendo a 33,43\% do total de saídas da Província. Ainda assim, como é possível verificar no quadro 2, a emigração também aqui se fez sentir com grande intensidade.

O distrito de Viseu, bastante mais populoso, assumiu a maior fatia da emigração total da Beira Alta. Deste distrito saíram, entre 1890 e 1939, 187385 emigrantes legais, correspondendo a $66,57 \%$ da emigração total da Beira Alta.

\section{Quadro 2 - Emigração nos distritos da Beira Alta (1890-1939)}

\begin{tabular}{|c|c|c|c|c|}
\hline \multirow[b]{2}{*}{ Anos } & \multicolumn{2}{|c|}{ Distrito de Viseu } & \multicolumn{2}{|c|}{ Distrito da Guarda } \\
\hline & $\begin{array}{l}\text { Número de } \\
\text { Emigrantes }\end{array}$ & Médias Anuais & $\begin{array}{l}\text { Número de } \\
\text { Emigrantes }\end{array}$ & $\begin{array}{l}\text { Médias } \\
\text { Anuais }\end{array}$ \\
\hline $1890-1899 .$. & 33857 & 3385,7 & 11226 & 1122,6 \\
\hline $1900-1909 \ldots$. & 38768 & 3876,8 & 15833 & 1583,3 \\
\hline $1910-1919 \ldots$ & 50743 & 5074,3 & 32571 & 3257,1 \\
\hline $1920-1929 \ldots \ldots \ldots \ldots \ldots \ldots$ & 46557 & 4655,7 & 26297 & 2629,7 \\
\hline $1930-1939 \ldots$ & 17460 & 1746,0 & 8197 & 819,7 \\
\hline TOTAL .................. & 187385 & 3747,7 & 94124 & 1882,4 \\
\hline
\end{tabular}

Fonte: (AMARO, 2006).

A emigração portuguesa, como temos vindo a referir, resulta de «uma deficiência estrutural e de conjunto»(GODINHO,1978, 24). Ainda assim, uma análise mais regionalizada desta questão permite encontrar especificidades que escapam às explicações mais globais. No caso da Beira Alta, a importante região dos vinhos do Dão, que tinha nesta cultura um dos principais recursos económicos e de grande ocupação de mão-de-obra assalariada, apresenta fluxos migratórios muito mais elevados. O quadro 3, onde se compara a emigração da Região do

\footnotetext{
${ }^{4}$ Comércio de Viseu, no 475, 1 de Fevereiro de 1891.
} 
Dão, com os restantes concelhos da Beira Alta, confirma que os municípios mais diretamente ligados à produção vinícola foram os mais afetados pela emigração.

\section{Quadro 3 - Emigração comparada: Região Demarcada do Dão e restantes concelhos da Beira Alta (1886-1921)}

\begin{tabular}{|c|c|c|c|c|c|c|}
\hline \multirow[b]{2}{*}{ Anos } & \multicolumn{3}{|c|}{ Concelhos integrados na Região Demarcada do Dão } & \multicolumn{3}{|c|}{$\begin{array}{l}\text { Concelhos da Beira Alta não integrados na Região } \\
\text { Demarcada do Dão }\end{array}$} \\
\hline & $\begin{array}{l}\text { População } \\
\text { Residente }\end{array}$ & $\begin{array}{l}\text { Total de } \\
\text { emigrantes }\end{array}$ & $\begin{array}{l}\text { Emigrantes } \\
\text { por } 1000 \\
\text { habitantes }\end{array}$ & $\begin{array}{l}\text { População } \\
\text { Residente }\end{array}$ & Total de emigrantes & $\begin{array}{l}\text { Emigrantes por } \\
1000 \text { habitantes }\end{array}$ \\
\hline $1886-1890$ & 251309 & 6423 & 25,55 & 399597 & 8631 & 21,59 \\
\hline $1905-1912$ & 267183 & 33034 & 123,63 & 429370 & 40434 & 94,17 \\
\hline 1914-1921 & 259999 & 21375 & 82,21 & 409571 & 22894 & 55,89 \\
\hline
\end{tabular}

Fontes: (AMARO, 2006); Movimento da População (1886-1890); Emigração Portuguesa (1905-1912) e Estatística Demográfica, Movimento da População (1914-1921).

Confirma-se para a região demarcada dos vinhos do Dão aquilo que alguns autores já destacaram para a região do Douro, quando encontraram uma estreita relação entre picos emigratórios regionais e as crises de produção e comercialização dos vinhos. Afonso Costa $(1911,176)$ reconhecia que «o distrito de Viseu, que é decerto a região do país que mais tem sofrido com a crise dos vinhos, é também aquela em que a emigração mais tem aumentado». A mesma opinião tinha Ezequiel de Campos ao admitir que, no distrito de Viseu, era o desequilíbrio económico que impelia a emigrar, «não tanto fundamentado na densidade da população, menor que a do litoral e decerto aquém da capacidade natural do terreno, mas filiado na depressão e até paralisação local da produção vinícola, com o correspondente embaraço da carestia da replantação e das crises comerciais» (CAMPOS, 1913, 93).

Curiosamente, estas análises mais desinteressadas e objetivas da emigração na Beira Alta não coincidiam com as leituras que se faziam no terreno. As leituras dominantes que se faziam em torno deste fenómeno ao nível regional eram interesseiras e contraditórias. Tanto as elites políticas locais como os proprietários agrícolas, preocupados com a falta de mão-de-obra e com os efeitos que esta tinha nos salários, dramatizavam como podiam a emigração, acentuando as causas subjetivas desta. As causas da emigração, no seus entenderes interessados, residiam antes de mais na «ganância» do emigrante, no «espírito de aventura» e no papel do engajador. Porém, muitas vezes sem se darem conta da contradição, reconheciam que o desemprego e a miséria eram insustentáveis. Por exemplo, no jornal O Comércio de Viseu, em 1912 (periódico ligado aos interesses dos proprietários vinícolas), um dos seus articulistas não escondia que a causa principal da emigração era «a falta de dinheiro e a ambição de em pouco ganhar muito. Nas aldeias, como mesmo nas cidades, falta o trabalho, não poucas vezes, e no geral é mal 
remunerado» $»^{5}$. E, para memória futura, ficou um retrato da realidade dos campos na Beira Alta, que ajuda a explicar a necessidade de tantos emigrarem:

a grande maioria do ano paga-se ao jornaleiro, a seco, ou quando muito dando-lhe meio ou um litro de vinho e a quantia de 200 réis. A mulher ganha 100 réis. Não falo do tempo das cavas de vinhas, ceifas, e outros trabalhos de importância, em que os salários aumentam até ao dobro, ou quase. É isto uma excepção, que não se estende a mais de uma quarta parte do ano. Convém frisar e este ponto é importantíssimo que em grande parte dos povos esse mísero jornal de 200 ou 100 réis não se ganha quando se quer e precisa, e até que se passam meses, e, pelo menos semanas, em que o pobre trabalhador não ganha real, porque não tem quem lhe dê trabalho. Calcule-se agora o que há-de ser e como há-de viver essa pobre gente que não tem nada de seu e que dá 160 e 180 e 200 réis por um pão que, para não ficar com fome, não lhe dura para mais de dois dias e 2 dias e meio» ${ }^{6}$.

Alguns anos depois, a complexidade do fenómeno migratório e a necessidade de o explicar não faziam diminuir as contradições. Atente-se, por exemplo, na resposta do Governador Civil da Guarda a um inquérito realizado pelo Boletim de Emigração (1921, n. $\left.{ }^{\circ} 1,1\right)$ : «no distrito da Guarda, onde não tem havido falta de braços e os salários têm sido bastante convidativos, nota-se falta de braços, devido ao espírito aventureiro e à oferta tentadora de salários na América do Norte». Eram, portanto, raros os atores e influentes locais e regionais que - não obstante reconhecerem a falta de trabalho e mesmo os baixos salários - defendiam a emigração. Quando muito, concordavam que se desviasse a emigração para as colónias africanas.

Às preocupações da(s) burguesia(s) agrária(s) - nomeadamente dos proprietários ligados à viticultura - tentavam responder os responsáveis políticos, procurando manter a emigração dentro do razoável. Em 1896, o Governador Civil de Viseu advertia todos Administradores de Concelho do distrito para se absterem de facilitar a emigração, dado que esta estava «muito longe de favorecer o bem público», pois esta desviava «do Continente e das Colónias os elementos indispensáveis ao seu desenvolvimento moral e material» ${ }^{7}$.

Esta última questão - que antecipa o controverso debate sobre os benefícios e malefícios da emigração para o desenvolvimento - conduz-nos de imediato ao ponto seguinte. A emigração, como temos vindo a referir, não se reduz a um mero problema demográfico, tem manifestamente implicações no desenvolvimento económico. E, neste sentido, emerge como elemento central o conhecimento prévio do perfil do emigrante.

\footnotetext{
${ }^{5}$ O Comércio de Viseu, n. ${ }^{\circ} 2723,5$ de Outbro de 1912.

${ }^{6}$ O Comércio de Viseu, n. ${ }^{\circ} 2723,5$ de Outubro, de 1912.

${ }^{7}$ Arquivo Distrital De Viseu (ADV), Fundo do Governo Civil - Correspondência Expedida para Administradores dos Concelhos, Caixa 46, nº2.
} 


\section{PERFIL DO EMIGRANTE DA BEIRA ALTA}

A emigração contribuiu, de facto, para aliviar a pressão social sobre certas regiões, assumindo-se como uma espécie de «válvula de segurança» (ALMEIDA e BARRETO (1970: 257). Porém, os fluxos migratórios intensos e permanentes, ao retirarem de certas regiões partes importantes da sua população mais jovem, dinâmica e produtiva, não absorveram apenas, como algumas correntes tendem a considerar, a mão-de-obra desempregada ou subempregada. No fundo, os países de imigração, direta e/ou indiretamente, outra coisa não fizeram que uma criteriosa seleção de recursos humanos - seleção física, médica, moral, intelectual, sexual, profissional, etc. -, com implicações económicas e sociais desiguais para os países envolvidos.

Por outro lado, se tivermos em conta que são normalmente as regiões mais pobres que alimentam os fluxos inter-regionais de trabalho, facilmente se conclui que a fuga persistente dos mais novos e inconformados acaba por comprometer o seu desenvolvimento económico. Nesta perspectiva, vejamos então qual era o perfil do emigrante da Beira Alta, no período aqui considerado.

\section{1. Sexo e idade dos emigrantes}

O perfil do emigrante da Beira Alta é em tudo semelhante ao de outras regiões portuguesas. Tal como no resto do país, também aqui a emigração foi essencialmente masculina. É possível, no entanto, verificar no quadro 4, o crescimento da emigração feminina no período de 1914-1921 $(35,60 \%)$. Esta maior representação feminina - que, aliás, já se vinha acentuando desde 1890 encontra explicação em duas mudanças importantes: por um lado, no crescimento da emigração familiar; por outro, no aumento da partida de mulheres casadas que pretendiam, assim, juntar-se aos maridos emigrados.

Quadro 4 - Beira Alta: emigração por sexos (1890-1934)

\begin{tabular}{|c|c|c|c|c|c|}
\hline \multirow[t]{2}{*}{ Anos } & \multirow[t]{2}{*}{ Emigrantes } & \multicolumn{2}{|l|}{ Homens } & \multicolumn{2}{|c|}{ Mulheres } \\
\hline & & $\mathrm{N}^{\mathrm{o}}$ & $\%$ & $\mathrm{~N}^{\circ}$ & $\%$ \\
\hline 1890-1896................... & 33732 & 25738 & 76,30 & 7994 & 23,70 \\
\hline 1899-1913 ................. & 114587 & 86778 & 75,73 & 27809 & 24,27 \\
\hline 1914-1921 ....................... & 44209 & 28474 & 64,40 & 15735 & 35,60 \\
\hline 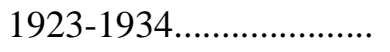 & 55523 & 40088 & 72,20 & 15435 & 27,80 \\
\hline Total. & 248051 & 181078 & 73,00 & 66973 & 27,00 \\
\hline
\end{tabular}

Fonte: (AMARO, 2006). 
Uma das consequências negativas da emigração predominantemente masculina - além dos possíveis desequilíbrios especificamente demográficos (taxas de nupcialidade, natalidade, etc.) - residiu na feminização das forças produtivas regionais, por via da diminuição da percentagem de homens na idade ativa (AMARO, 2006). Com os maridos emigrados, muitas mulheres pouco mais poderiam fazer do que manter o património familiar - muitas vezes apenas possível com a ajuda das poupanças e remessas enviadas por aqueles - e só excecionalmente investiam em mudanças estruturais ou na modernização das suas explorações agrícolas.

À semelhança do resto do país, a emigração na Beira Alta incidiu essencialmente sobre a população adulta. Entre 1890 e 1934, apenas 13,30\% dos emigrantes apresentavam ter menos de 14 anos (quadro 5). As estatísticas oficiais, infelizmente, não permitem que se faça uma análise mais fina e completa. Até 1940, as fontes disponíveis apenas separam os emigrantes maiores e menores de 14 anos, não diferenciando a idade dos adultos. Porém, tendo em conta outros indicadores, pode dizer-se com alguma segurança que o grosso da emigração se situava no intervalo entre os 20 e os 40 anos.

Quadro 5 - Beira Alta: emigração por idades (1890-1934)

\begin{tabular}{|c|c|c|c|c|c|}
\hline \multirow[t]{2}{*}{ Anos } & \multirow[t]{2}{*}{ Emigrantes } & \multicolumn{2}{|c|}{$\begin{array}{l}\text { Emigrantes } \\
\text { com }>14 \text { anos }\end{array}$} & \multicolumn{2}{|c|}{$\begin{array}{l}\text { Emigrantes com } \\
<\text { de } 14 \text { anos }\end{array}$} \\
\hline & & $\mathrm{N}^{\circ}$ & $\%$ & $\mathrm{~N}^{\circ}$ & $\%$ \\
\hline 1890-1896................... & 33732 & 26921 & 79,80 & 6811 & 20,20 \\
\hline 1899-1913 ...................... & 114587 & 98012 & 85,53 & 16575 & 14,46 \\
\hline 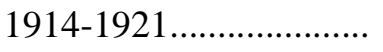 & 44209 & 37600 & 85,05 & 6609 & 14,95 \\
\hline 1923-1934......................... & 55523 & 52547 & 94,64 & 2976 & 5,36 \\
\hline Total..... & 248051 & 215080 & 86,70 & 32971 & 13,30 \\
\hline
\end{tabular}

Fonte: (AMARO, 2006).

Destaque-se, no entanto, o facto de os menores de 14 anos, no período de 1890-1896, terem superado os $20 \%$ do total dos emigrantes. Estes valores são, apesar de tudo, significativos, mas não se trata, mais uma vez, de um fenómeno localizado ou regional. $\mathrm{O}$ crescimento da emigração de menores, neste período, afetou de igual modo outras regiões do país (EVANGELISTA 1971,125-126), sendo a percentagem de Portugal Continental muito semelhante à da Beira Alta (20,2\%, em 1891-1900).

Ainda que, como referimos, este crescimento na emigração de menores não fosse específico da Beira Alta, importa determo-nos sobre alguns dos condicionalismos que o explicam. Entre as causas e tendências mais gerais - como o reagrupar de famílias, a fuga ao serviço militar - no caso da Beira Alta uma outra razão parece ter sido determinante. Referimo- 
nos, em concreto, ao aumento crescente da pressão sobre a terra. A emigração dos filhos menores obedecia, muitas vezes, a uma estratégia familiar para evitar a todo custo a falência da pequena exploração e a consequente proletarização do conjunto do agregado.

Aliás, as remessas dos emigrantes viriam a servir também para evitar não só a falência da pequena exploração agrícola, como impediram em muitos casos a aceleração das relações capitalistas na agricultura. Levando a que a emigração tivesse nesta região de pequena propriedade familiar efeitos sociais contraditórios: por um lado, a emigração era o custo a pagar pela pobreza nos campos; por outro, o que resultava das suas poupanças era a tentativa de manutenção de um sistema de propriedade inviável que não garantia a necessária sobrevivência económica e social.

\section{Quadro 6 - Indicadores sociodemográficos da Beira Alta (1890-1940)}

\begin{tabular}{lllll}
\hline Anos & $\begin{array}{l}\text { Índice de } \\
\text { envelhecimento }\end{array}$ & $\begin{array}{l}\text { Taxa de } \\
\text { dependência }\end{array}$ & $\begin{array}{l}\text { Relação de } \\
\text { Substituição }\end{array}$ & $\begin{array}{l}\text { Relação de } \\
\text { masculinidade }\end{array}$ \\
\hline $1890 \ldots \ldots \ldots \ldots \ldots$ & 23,45 & 117,21 & 1,73 & 79,99 \\
$1920 \ldots \ldots \ldots \ldots \ldots . . \ldots \ldots$ & 23,82 & 121,91 & 1,87 & 73,97 \\
$1940 \ldots \ldots \ldots \ldots \ldots$ & 25,38 & 123,87 & 2,03 & 83,32 \\
\hline
\end{tabular}

Fonte: Recenseamentos Gerais da População (1890; 1920; 1940).

Igualmente negativos para o desenvolvimento da região foram os efeitos da emigração sobre a estrutura sociodemográfica. A informação reunida no quadro 6 não deixa dúvidas sobre as consequências da emigração, em vertentes demográficas tão importantes como os índices de envelhecimento da população, taxas de dependência, níveis de substituição entre gerações e a evolução da relação entre homens e mulheres. É possível verificar que, em todos os indicadores apresentados, as marcas da emigração estão bem presentes, com destaque para o índice de população masculina que, em 1920, na ultrapassa os $73,97 \%$.

Ou seja, por cada 100 mulheres com idades compreendidas entre os 20 e os 59 anos, apenas cerca de 74 homens. É difícil medir este efeito de feminização sobre o desenvolvimento de um território que tem na agricultura familiar o principal sustento, em que tradicionalmente a iniciativa e a modernização da exploração agrícola eram competência masculina. Mas, tudo indica que a incapacidade de modernização da agricultura e de outros setores económicos encontra também aqui uma parte significativa da sua explicação. 


\subsection{Nível de instrução e situação profissional}

As estatísticas oficiais são, infelizmente, bastante deficitárias e incompletas na caracterização dos níveis de instrução e situação profissional dos emigrantes. Acresce ainda que, como se já não bastasse esse facto, as metodologias seguidas na recolha dos dados, ao longo do período aqui focado, não se mantiveram constantes. Entre muitos exemplos possíveis, destaquese o facto de a desagregação por distritos, entre os emigrantes analfabetos e os que sabiam ler e escrever, terminar em 1921. O mesmo acontece com a informação sobre as profissões dos emigrantes, a nível distrital, que é interrompida em 1921. Por sua vez, mesmo entre 1890 e 1921 , nos casos apresentados, não foi possível obter informação para todos os anos.

Por outro lado, a forma como foi feita a recolha da informação não está isenta de levar a alguns equívocos. Por exemplo, o que devemos entender por saber ler e escrever, categoria que distingue os emigrantes alfabetizados dos que não dominam estes princípios elementares? No primeiro caso, estamos perante um emigrante com que nível de escolaridade? Trata-se de conhecimentos elementares médios ou superiores?

No que respeita aos dados recolhidos sobre as profissões dos emigrantes (quadro 9), além das limitações referidas, acrescem as que se prendem com a elevada percentagem dos que não fazem referência a qualquer profissão. Estaremos, neste caso, na presença de emigrantes sem qualquer ocupação, ou tratar-se-á, simplesmente, de emigrantes menores e ainda não integrados na vida ativa? Provavelmente nunca o saberemos ao certo, mas registe-se o facto de, entre 1905 e 1912, este tipo de resposta ter sido dada por $25 \%$ do total dos emigrantes legais.

Quadro 7 - Nível de instrução dos emigrantes da Beira Alta (1890-1921)

\begin{tabular}{|c|c|c|c|c|c|}
\hline \multirow[b]{2}{*}{ Anos } & \multirow[b]{2}{*}{ Emigrantes } & \multicolumn{2}{|c|}{ Analfabetos } & \multicolumn{2}{|c|}{ Sabe ler e escrever } \\
\hline & & $N^{o}$ & $\%$ & $N^{o}$ & $\%$ \\
\hline 1890-1896........................ & 24226 & 16583 & 68,45 & 7643 & 31,55 \\
\hline 1902-1912.. & 80131 & 50932 & 63,56 & 29199 & 36,44 \\
\hline 1914-1921 …................. & 34517 & 19366 & 56,10 & 15151 & 43,90 \\
\hline Total.. & 138874 & 86881 & 62,56 & 51993 & 37,44 \\
\hline
\end{tabular}

Fonte: (AMARO, 2006).

Apesar das dificuldades metodológicas referidas, a análise da informação apresentada nos quadros 7 e 8 permite que se retirem as seguintes conclusões:

a) Ao contrário do que seria de esperar, mesmo nos períodos de emigração mais intensa, a tendência foi para que o peso de emigrantes alfabetizados fosse cada vez maior. Se, no 
primeiro período considerado (quadro7), apenas 31,55\% dos emigrantes legais sabiam ler e escrever, no último a percentagem atingia já os $43,90 \%$.

b) Registe-se, também, o facto de, à medida que nos aproximamos do final da década de vinte, diminuir a percentagem de emigrantes analfabetos (quadro 8). Tendência que, aliás, se acentuou após a crise de 1929, por via das dificuldades que entretanto se colocaram à emigração menos qualificada.

Caso analisássemos os níveis de instrução da emigração oriunda da Beira Alta de forma isolada, poderíamos ser induzidos a afirmar que, afinal, estávamos perante um fluxo migratório, apesar de tudo, de população analfabeta e, porventura, excedentária. Ou mesmo sermos levados a concluir que se tratava de uma parte da população dispensável, em termos do desenvolvimento económico regional.

Quadro 8 - População emigrante analfabeta (1890-1933) (em percentagem)

\begin{tabular}{lll}
\hline Anos $^{8}$ & Distrito de Viseu & Distrito da Guarda \\
\hline 1890 & 70,50 & 74,82 \\
1891 & 74,85 & 72,36 \\
1892 & 64,08 & 69,56 \\
1893 & 66,92 & 67,96 \\
1894 & 68,46 & 66,75 \\
1895 & 69,78 & 72,03 \\
1896 & 65,60 & 70,10 \\
1902 & 58,42 & 60,88 \\
1903 & 55,34 & 56,11 \\
1904 & 57,23 & 61,41 \\
1905 & 55,16 & 59,01 \\
1906 & 54,04 & 57,60 \\
1907 & 58,06 & 54,79 \\
1908 & 63,73 & 60,48 \\
1909 & 60,61 & 78,17 \\
1910 & 57,75 & 75,36 \\
1911 & 60,20 & 77,61 \\
1912 & 66,45 & 79,25 \\
1914 & 66,53 & 73,94 \\
1915 & 62,62 & 75,44 \\
1916 & 70,46 & 84,51 \\
\hline
\end{tabular}

\footnotetext{
${ }^{8}$ Fontes estatísticas oficiais apresentam lacunas nos dados distritais para alguns anos (entre 1897 e 1901) e, no caso do distrito da Guarda, para os anos 1923-1924. Após 1933, as estatísticas deixaram de considerar os dados distritais.
} 


\begin{tabular}{lll}
\hline 1917 & 62,04 & 79,44 \\
1918 & 61,42 & 71,27 \\
1919 & 51,50 & 63,24 \\
1920 & 41,45 & 35,83 \\
1921 & 51,72 & 71,51 \\
1922 & 58,87 & 55,36 \\
1923 & 57,90 & - \\
1924 & 59,47 & - \\
1925 & 53,97 & 85,89 \\
1926 & 53,81 & 66,03 \\
1927 & 48,31 & 48,73 \\
1928 & 45,49 & 51,19 \\
1929 & 48,52 & 53,28 \\
1930 & 41,52 & 46,97 \\
1931 & 43,26 & 38,27 \\
1932 & 13,02 & 30,33 \\
1933 & 21,11 & 21,83 \\
\hline
\end{tabular}

Fontes: de 1890 a 1896, Movimento da população; de 1897 a 1900 e de 1922 a 1940, Anuário Estatístico de Portugal; de 1901 a 1912, Emigração Portuguesa; de 1913 a 1921, Estatística Demográfica, Movimento da População.

Acontece, porém, que o problema da Beira Alta - tal como o de outras regiões que sofreram uma emigração intensa e prolongada - não pode ser visto apenas no quadro de uma suposta abundância de mão-de-obra. O enfoque, a nosso ver, deve colocar-se mais a nível qualitativo do que quantitativo e tendo em conta as necessidades de modernização das estruturas produtivas, bem como a realidade dos recursos humanos existentes na região.

Assim sendo e na falta de melhor indicador comparativo, atente-se, por exemplo, no seguinte: nos inícios do século XX, 65\% dos residentes da Beira Alta, com mais de sete anos, eram totalmente analfabetos; algumas décadas mais tarde (1930-1940), os índices de alfabetização pouco tinham evoluído e variavam ainda entre os 30-40\%. Ora, perante este quadro de alfabetização regional, é possível dizer-se - tendo em conta o nível de instrução dos emigrantes - que estamos perante uma população dispensável? Ou, pelo contrário, teremos que admitir que, fosse qual fosse a percentagem de emigrantes com instrução, seria sempre, em qualquer caso, uma enorme perda para o desenvolvimento da Beira Alta?

Antes de mais, as perguntas anteriores conduzem a uma nova questão que, no fundo, contém já em si uma parte importante daquilo que poderá ser a nossa resposta: podia esta região almejar a outra coisa que não fosse ao subdesenvolvimento, quando, tendo mais de $60 \%$ de 
analfabetos, deixava todos os dias partir recursos humanos alfabetizados, em percentagens que chegaram a atingir os 50, 60 e mesmo $80 \%$ ?

A resposta, às questões colocadas anteriormente, parece-nos não poder ser muito diferente desta: a emigração contribuiu de forma decisiva e direta para que a Beira Alta hipotecasse muito daquilo que poderia ter sido o seu desenvolvimento económico normal (ALVES,1994,29-30).

Seletiva por definição, a emigração acabou por ser uma das principais responsáveis por dois aspetos essenciais e complementares, em termos de desenvolvimento regional: por um lado, pelo constante empobrecimento dos recursos humanos locais e regionais; por outro, pelo subaproveitamento dos principais recursos endógenos.

Não queremos, com isto, contraditar aqueles que consideram que o subdesenvolvimento é, em muitas circunstâncias históricas, muito mais a causa do que o produto da emigração (PEREIRA,1983, 33). Muito pelo contrário, pretendemos tão-só vincar que o fenómeno emigratório - sobretudo quando assume a dimensão e a persistência que teve na Beira Alta tornou ainda mais fechado o ciclo vicioso de pobreza que, afinal, sustentou a emigração.

Quadro 9 - Emigração na Beira Alta por sectores de actividade (1890-1921)

\begin{tabular}{|c|c|c|c|}
\hline Sectores de actividade & $1890-1894$ & 1905-1912 & 1914-1921 \\
\hline I - Sector Primário.......................... & 9241 & 39520 & 17171 \\
\hline Lavrador................................. & 235 & & \\
\hline Agricultor............................ & 1744 & 12632 & \\
\hline Jornaleiro .............................. & 6265 & 20180 & 14583 \\
\hline Proprietário........................... & 997 & 6708 & 2588 \\
\hline II - Sector Secundário................ & 1446 & 6629 & 2436 \\
\hline Pedreiro............................. & 184 & 1125 & 360 \\
\hline Carpinteiro......................... & 307 & 1606 & 617 \\
\hline Caiador............................ & 21 & 272 & 84 \\
\hline Ferreiro....................... & 22 & 236 & 194 \\
\hline Padeiro............................. & 6 & & \\
\hline Industrial.......... & 26 & 7 & 30 \\
\hline Operário fabril......................... & 26 & 314 & 175 \\
\hline Sapateiro........................... & 44 & 540 & 251 \\
\hline Alfaiate.......... & 211 & 860 & 353 \\
\hline Costureira......................... & 28 & & \\
\hline Artesão................................... & 571 & 1669 & 372 \\
\hline III - Sector Terciário.................. & 532 & 2408 & 1515 \\
\hline Comerciante......................... & 166 & 531 & 381 \\
\hline Empregado do comércio................ & 200 & 1248 & 834 \\
\hline Funcionário público..................... & 6 & 8 & 11 \\
\hline Barbeiro.......................... & 133 & 536 & 216 \\
\hline Serviço de Transportes.............. & 8 & 20 & \\
\hline Padre............................... & 7 & & \\
\hline Intelectual.................... & 12 & 65 & 73 \\
\hline IV - Criados/Criadas, Domésticas... & 173 & 2294 & 8811 \\
\hline V - Sem profissão/Não refere.......... & 5203 & 17032 & 5384 \\
\hline Total de emigrantes.................. & 16595 & 67883 & 35317 \\
\hline
\end{tabular}

Fontes: de 1890 a 1894, Movimento da população; de 1905 a 1912, Emigração Portuguesa; de 1914 a 1921 , Estatística Demográfica, Movimento da População. 
O quadro 9, sobre a emigração por setores de atividade, não deixa dúvidas sobre a ocupação dos emigrantes. Eram maioritariamente agricultores e sobretudo jornaleiros. Os emigrantes ligados aos sectores secundário e terciário - mão-de-obra mais qualificada e economicamente menos dispensável - nunca representaram, em conjunto e nos períodos considerados, mais do que $13 \%$ do total de emigrantes. Ainda assim, saliente-se o facto de quase nenhum setor de atividade económica ou profissão ter ficado totalmente imune à emigração. Com destaque para as profissões tradicionais, como pedreiros, carpinteiros, alfaiates e empregados do comércio.

Foi, portanto, a falta de modernização económica que levou à falta de trabalho na região e à emigração, do mesmo modo que o ambiente criado por esta - as redes familiares e de engajadores, bem como as expectativas de fortunas reais e imaginárias - alimentou a roda que a tornou ainda mais intensa. E, com o tempo, o êxodo não foi apenas de uma mão-de-obra agrícola excedentária, mas também de muitos outros profissionais qualificados, em percentagens não desprezíveis.

\section{DESTINOS DA EMIGRAÇÃO}

Tal como nas restantes regiões do continente português, os emigrantes originários da Beira Alta escolheram o Brasil como principal país de destino (quadro 10).

Ainda que, a nível distrital, existam algumas diferenças nesta escolha - o Brasil foi o país escolhido por $91,67 \%$ dos emigrantes provenientes do distrito de Viseu, enquanto que no distrito da Guarda apenas 72,63\% o fizeram -, em qualquer dos casos, a procura de outras paragens foi pouco mais que residual. Destaque-se apenas a emigração para os EUA que atingiu na Beira Alta quase $6 \%$, muito embora, também neste caso, com importantes diferenças distritais: enquanto que no distrito de Viseu a emigração para a América do Norte não foi além dos 2,74\%; no distrito da Guarda atingiu os 12,34\%. Esta preferência pelos EUA, por parte dos emigrantes do distrito da Guarda, foi, sobretudo, marcante entre 1907 e 1920. Em alguns anos deste período - por exemplo, 1916 e 1920 -, os emigrantes com destino àquele país suplantaram mesmo os que rumavam ao Brasil $^{9}$.

\footnotetext{
9 Saliente-se que, em 1920, o Governador Civil da Guarda mostrava alguma preocupação com a falta de braços na região, precisamente devido à oferta tentadora de altos salários que provinha da América do Norte (Boletim da Emigração, no 4, 1920, p. 10). De facto, no ano de 1920, com destino aos EUA, saíram do distrito da Guarda 2833 emigrantes.
} 
Quadro 10 - Destinos dos emigrantes da Beira Alta (1890-1934) ${ }^{10}$

\begin{tabular}{|c|c|c|c|c|c|c|}
\hline \multirow[b]{2}{*}{ Destinos } & \multicolumn{2}{|c|}{ Distrito de Viseu } & \multicolumn{2}{|c|}{ Distrito da Guarda } & \multicolumn{2}{|l|}{ Beira Alta } \\
\hline & $N^{o}$ Emigrantes & $\%$ & $N^{o}$ Emigrantes & $\%$ & $N^{o}$ Emigrantes & $\%$ \\
\hline Brasil. & 152365 & 91,67 & 59429 & 72,63 & 211794 & 85,39 \\
\hline África. & 3556 & 2,14 & 2817 & 3,44 & 6373 & 2,57 \\
\hline EUA. & 4558 & 2,74 & 10098 & 12,34 & 14656 & 5,91 \\
\hline América do Sul... & 1311 & 0,79 & 7512 & 9,18 & 8823 & 3,56 \\
\hline Outros destinos.. & 4427 & 2,66 & 1972 & 2,41 & 6399 & 2,57 \\
\hline TOTAL....... & 166217 & 100,00 & 81828 & 100,00 & 248045 & 100,00 \\
\hline
\end{tabular}

Fonte: (AMARO, 2006).

Não obstante as diferenças referidas, não há dúvidas que as facilidades com a língua e os laços históricos e culturais mantidos entre os dois países acabaram por ser determinantes para que 85,39\% dos emigrantes da Beira Alta optassem pelo Brasil. No entanto, como têm salientado vários autores, esta preferência pelo Brasil não foi totalmente espontânea; como, aliás, não é, nem nunca foi, característica de qualquer movimento migratório (PEREIRA, 1981, 15-20).

Não vamos repetir aqui as várias condicionantes, externas e internas, que levam à emigração para determinado país, mas importa referir que em nenhuma circunstância a mobilidade do trabalho se faz de forma absolutamente livre e automática. A decisão de partir e a opção por um país de imigração exige a conjunção de múltiplos fatores; entre os quais, não são despiciendas as políticas de emigração seguidas, as redes familiares, institucionais e informais.

De facto, o Brasil desenvolveu em Portugal - mercê das relações privilegiadas já aludidas, que lhe permitiam outras facilidades e contactos, relativamente a outros países também carentes de mão-de-obra - aquilo a que podemos chamar uma política de imigração agressiva, sem comparação possível com qualquer outro país de destino. O recrutamento de emigrantes, escreveu M. Halpern Pereira (1981, 18), foi «objeto de uma atividade organizada sob a forma empresarial e várias companhias e engajadores empenhados neste negócio recebiam subsídios do governo brasileiro ou trabalhavam diretamente para governos federais».

Por outro lado, a política de emigração ambígua e contraditória do Estado português também ajudou ao êxito da política de recrutamento por parte dos responsáveis brasileiros. As autoridades portuguesas, por um lado, viam-se obrigadas a reconhecer não poder dispensar as divisas provenientes do Brasil; por outro, faziam a propaganda das virtudes patrióticas e económicas da emigração para as colónias; e, por último, esforçavam-se por manter a emigração

\footnotetext{
${ }^{10}$ As fontes estatísticas, entre 1934 e 1940, não desagregaram por distritos os destinos dos emigrantes. Por sua vez, para o distrito da Guarda não foi possível obter valores sobre os destinos da emigração para os anos 1897-1898 e 1922-1924; quanto ao distrito de Viseu, não foi possível obter dados para os anos 1897-1898 e 1922.
} 
em níveis aceitáveis, para não descontentar as burguesias rurais e não colocar em causa o próprio sistema económico vigente.

O quadro apresentado revela, ainda, que, à semelhança do que se passou no resto do país, também não tiveram qualquer êxito na Beira Alta - não obstante a sucessão de medidas legislativas ${ }^{11}$ favoráveis à emigração para as colónias e o apoio das elites regionais- os constantes apelos para que se orientasse parte substancial da emigração para África (PEREIRA, 1981, 53 54). Nos primeiros anos da década do século (1900-1906) ainda se nota um pequeno acréscimo de emigrantes com aquele destino, mas, globalmente, os resultados são pouco mais do que marginais (2,57\%). Razão tinham os responsáveis pelo Boletim de Emigração que, em 1920, consideravam que até então apenas se tinham feito «algumas tentativas, mal dirigidas, de colonização europeia no distrito de Luanda, que abortaram completamente, porque eram destituídas de método e da necessária preparação, de maneira que os colonos, desalentados pela inclemência do clima e sobretudo pela falta de recursos, faleceram uns e dispersaram-se os sobreviventes» ${ }^{12}$. A inversão desta situação, no entender dos mesmos responsáveis pelo Boletim de Emigração, passava pela:

a) «criação de companhias de colonização, por meio de uma cautelosa e bem entendida lei de concessões», com «garantias de nacionalização das regiões», entre as «quais a da fixação dum certo número de famílias aptas em cada zona»;

b) transformação das companhias em «fortes núcleos de colonização, pelo estabelecimento das mais perfeitas condições de vida, indispensáveis ao europeu em tais climas»;

c) «criação duma agência oficial de informação colonial, com sucursais nas capitais de distrito para utilização dos industriais, colonos, comerciantes e dos próprios emigrantes», funcionando como «centro de propaganda colonial» ${ }^{13}$.

Apesar de todas estas tentativas de desviar parte da emigração do Brasil, em benefício das colónias africanas, pelo proveito que daí pensavam retirar os sectores da sociedade mais ligados à produção e comércio de produtos excedentários, a emigração para o Brasil só viria a diminuir, quando a crise económica e financeira de 1929 obrigou aquele país a restringi-la. Mas nem assim

\footnotetext{
${ }^{11}$ As primeiras medidas para encorajar a emigração para as colónias africanas, tomadas em 1877, foram reforçadas pela gratuitidade dos passaportes para a África estabelecida em 1896 e seguida pela sua supressão em 1907. Paralelamente, o preço dos passaportes de emigrantes com outros destinos foi aumentado. De 1907 em diante, só os emigrantes que não se destinavam ao Ultramar continuavam a precisar de passaporte.

${ }^{12}$ Boletim de Emigração, n. ${ }^{\circ} 2-3,1920$, p. 39.

${ }^{13}$ Boletim de Emigração, n. ${ }^{\circ} 2-3,1920$, p. 41-42.
} 
as colónias, também elas afetadas pela crise, mostraram poder alguma vez assumir-se como alternativa.

Analisado que foi, durante 50 anos (1890-1939), o fenómeno migratório da Beira Alta, é possível dizer que esta Província portuguesa era, no final do período considerado, uma região demográfica e socioeconomicamente mais pobre. Bem sabemos que dificilmente se pode estabelecer uma relação direta entre emigração e subdesenvolvimento económico. Porém, no caso da Beira Alta, são tantos os indicadores que apontam no mesmo sentido que dificilmente se podem isentar os efeitos negativos da emigração. Esta região, registava os maiores índices de repulsão do país e, por via disso, a sua população cresceu sempre menos do que a média nacional, apresentando uma estrutura demográfica bastante desequilibrada, tanto em termos etários como na sua distribuição por sexos. O intenso êxodo rural nunca serviu para alimentar o crescimento das principais cidades da região, mas sim para engrossar a emigração, provocando uma importante sangria dos recursos humanos regionais menos acomodados e mais pujantes (AMARO, 2006).

\section{CONCLUSÕES}

São muitos os autores que encaram a emigração numa estrita visão economicista, atribuindo-lhe uma racionalidade que não vislumbrámos no caso concreto da Beira Alta. A emigração é vista, sobretudo pelas teorias neoclássicas, no quadro imóvel das vantagens comparativas e da mobilidade natural do trabalho, onde tudo se equilibra, acabando no final por beneficiar, tanto os países de origem como de destino. Desde logo, permite a eliminação da força de trabalho excedentária, contribuindo para elevar os níveis de produtividade dos países e regiões (RODRÍGUEZ, 2000, p.157-192).

Acrescentam ainda a estes aspetos positivos os efeitos macroeconómicos, nomeadamente os contributos das remessas dos emigrantes para a balança de pagamentos, uma maior disponibilidade de divisas, ou mesmo o investimento direto nas regiões, proveniente das poupanças efetuadas. Muitas destas abordagens, centradas no equilíbrio do mercado e nos efeitos macroeconómicos da emigração, raramente distinguem os seus efeitos globais e nacionais dos impactos assimétricos sobre as regiões menos competitivas.

O crescimento económico nacional não resulta sempre, como é sabido, em desenvolvimento regional, as assimetrias regionais profundas ainda hoje existentes em Portugal, 
não sendo na sua totalidade consequência da emigração, são, contudo, o exemplo de que o desenvolvimento regional não acompanhou o crescimento nacional.

A realidade regional da Beira Alta desmente categoricamente os supostos efeitos de arrastamento e difusão dos ganhos nacionais obtidos com a emigração. Por exemplo, as remessas dos emigrantes que, em termos do crescimento económico nacional tiveram efeitos extraordinários - influência positiva sobre a balança de pagamentos, compra de bens de equipamento, matérias-primas e desenvolvimento de infraestruturas - acabaram por beneficiar, sem dúvida, as regiões mais ricas (COSTA e PORTO, 1984, p. 45-59).

Por outro lado, o comportamento positivo da emigração, na redução do subemprego, não teve o mesmo efeito nas regiões que, entretanto, se modernizaram e nas que mantiveram estruturas produtivas tradicionais. Nas regiões mais pobres, como era o caso da Beira Alta, o equilíbrio inicial que a emigração supostamente trouxe ao mercado de trabalho acabou por desaparecer, sobretudo em termos qualitativos, tornando ainda mais difícil a necessária modernização económica.

Os efeitos negativos da emigração, pelo facto de terem perdurado no tempo, acabaram por contribuir para que este território chegasse à década de sessenta do século passado, quando as assimetrias regionais ainda se cavaram mais profundamente, com os mais baixos índices de desenvolvimento do continente português.

\section{REFERÊNCIAS}

ALMEIDA, Carlos e BARRETO, António (1970), Capitalismo e Emigração em Portugal, Lisboa, Prelo.

ALVES, Jorge Fernandes (1989), «Emigração portuguesa: o exemplo do Porto nos meados do século XIX», Revista de História, Vol. IX, Porto, p. 267-289.

ALVES, Jorge Fernandes (1994), Os Brasileiros. Emigração e Retorno no Porto Oitocentista, Porto. Edição de autor.

AMARO, António Rafael (2006), Economia e Desenvolvimento da Beira Alta. Dos Finais da Monarquia à II Guerra Mundial (1890-1939), Lisboa, Universidade Católica Editora.

ARROTEIA, Jorge Carvalho (1983), A Emigração Portuguesa: suas origens e evolução, Lisboa, Instituto de Cultura e Língua Portuguesa.

BAGANHA, Maria Joannis (1988), Internacional labor movements:portuguese emigration to the United States, 1820-1930 (dissert. de doutoramento apresentada na Universidade da Pennsylvania).

BAGANHA, Maria Joannis (1991), «Uma imagem desfocada - a emigração portuguesa e as fontes sobre a emigração», Análise Social, Vol. XXVI, n. ${ }^{\circ} 112-113$, p. 723-739. 
BAGANHA, Maria Joannis (1994), «As correntes emigratórias portuguesas no século XX e o seu impacte na economia nacional», Análise Social, Vol. XXIX, n. ${ }^{\circ} 128$, p. 959-980.

CAMPOS, Ezequiel de (1913), A Conservação da Riqueza Nacional. A Grei. Os Minerais. A Terra. As Matas. Os Rios, Porto, s.ed.

COSTA, Afonso (1911), Estudos de Economia Nacional I. O Problema da Emigração, Lisboa, Imprensa Nacional.

COSTA, Fernanda Maria ; PORTO, Manuel Lopes; (1984), «A emigração e o desenvolvimento regional em Portugal», Comissão de Coordenação da Região Centro, p. 45-60.

EVANGELISTA, João (1971), Um século de população portuguesa (1864-1960), Lisboa, Publicações do Centro de Estudos Demográficos.

GODINHO, Vitorino Magalhães (1978), «L'émigration portugaise (XV-XX siècles) - une constante structural et les réponses aux changements du monde», Revista de História Económica e Social, n. ${ }^{\circ}$, p. 5-32.

LEEDS, Elizabeth (1983), «Industrialização e emigração em Portugal: sintomas inevitáveis de uma doença estrutural», Análise Social, Vol. XIX, n. ${ }^{\circ}$ s 77-79, p. 1045-1081.

LEITE, Joaquim Costa (1987), «Emigração portuguesa: a lei e os números (1855-1914)», Análise Social, Vol. XXIII, n. ${ }^{\circ}$ 97, p. 463-480.

PEREIRA, Miriam Halpern (1981), A política portuguesa de emigração, 1850-1930, Lisboa, A Regra do Jogo.

PEREIRA, Miriam Halpern (dir.) (1993), Emigração/Imigração em Portugal (Actas do Colóquio Internacional sobre Emigração e Imigração em Portugal, séculos XIX e XX), Algés, Editorial Fragmentos.

PORTO, Manuel Lopes (1984), «Retorno, emigração e desenvolvimento regional: perspetivas de análise política», Estudos de Economia, Vol. IV, n. ${ }^{\circ}$ 4, p. 513-521.

SANTOS, Boaventura Sousa (org. 1993), Portugal: Um Retrato Singular, Porto, Edições Afrontamento

SERRÃO, Joel (1977), Emigração Portuguesa (Sondagem Histórica), Lisboa, Livros Horizonte.

SILVA, Manuela e Outros (1984), Retorno, Emigração e Desenvolvimento Regional em Portugal, Lisboa, Instituto de Estudos para o Desenvolvimento. 


\section{ANEXO 1: \\ Mapa de Portugal Continental com a Província da Beira Alta} (a laranja escuro)

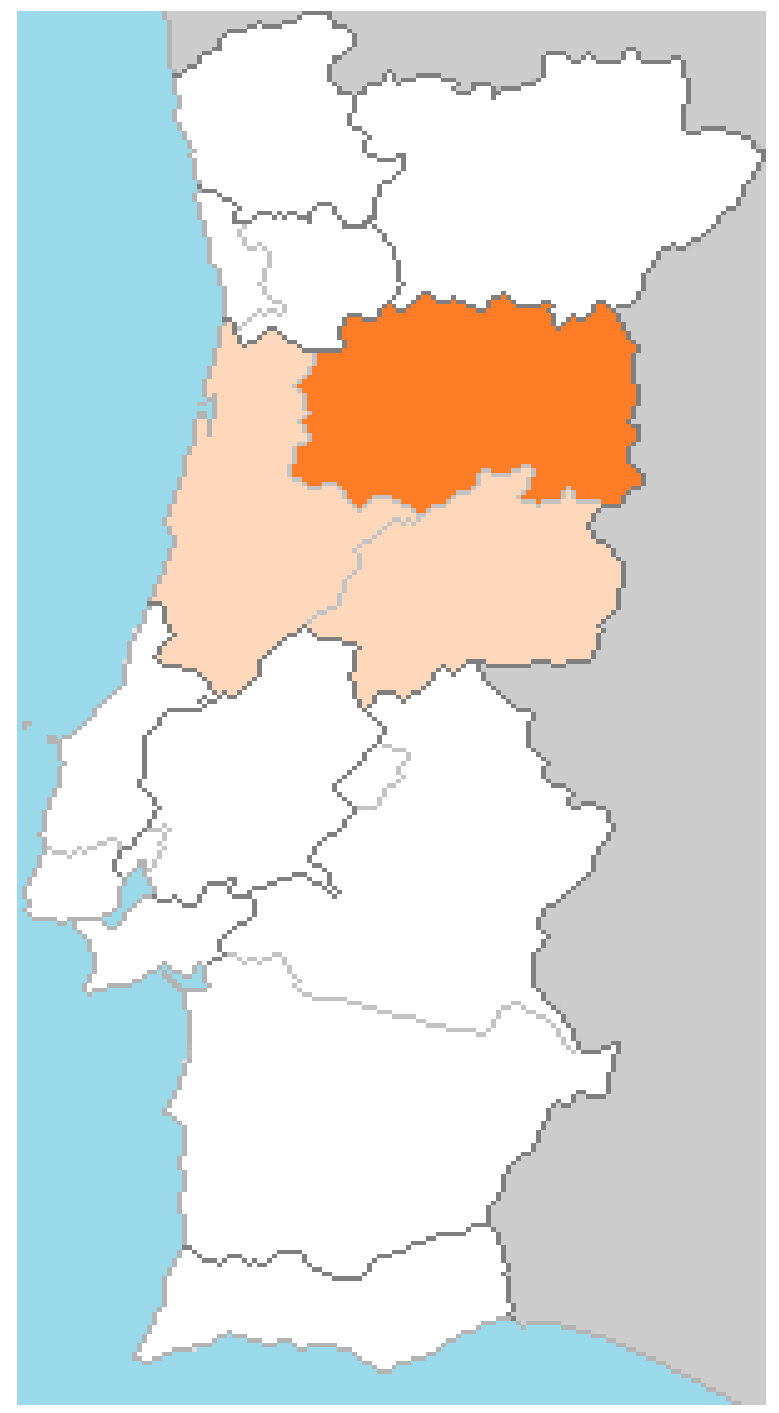

Recebido: 30/04/2019 